\title{
Congratulations on the 60th anniversary of the Korean Association of Oral and Maxillofacial Surgeons
}

\author{
Won Lee, D.D.S., M.S.D., Ph.D. \\ Associate Editor of JKAOMS \\ Department of Dentistry, Uijeongbu St. Mary's Hospital, College of Medicine, The Catholic University of Korea, Seoul, Korea
}

From March 21 to 23, 2019, the 60th congress of the Korean Association of Oral and Maxillofacial Surgeons (KAOMS) successfully took place at the International Convention Center (ICC) Jeju on Jeju Island, South Korea's southernmost province. This academic congress focused on the theme of "Reviewing the Old and Learning the New" to commemorate the 60th anniversary of the Association.

The 60th birthday is "hwangap" in Korea, which is usually celebrated with an elaborate party to celebrate the milestone and wish for continued good health and longevity.

The KAOMS has been dedicated to the field of dentistry for the 60 years since its establishment. In 1959, 36 dental surgeons gathered to form the Korean Association of Oral Surgeons (KAOS) and elected Professor Chun-Geun Lee of Seoul National University as the first President. In 1984, the KAOS changed its name to the Korean Association of Oral and Maxillofacial Surgeons. Currently, the KAOMS has more than 2,400 registered members including a total of 1,300 government-certified specialists in oral and maxillofacial surgery.

The KAOMS has established sisterhoods and academic agreements with Japan and other countries around the world to promote international academic exchanges and strengthen relationships. In 2000, the Asian Congress on Oral and Maxillofacial Surgery (ACOMS) was held on Jeju Island. In 2007 and 2014, the Korean-American-Japanese Joint Academic

\footnotetext{
Won Lee

Dental Clinic, Uijeongbu St. Mary's Hospital, 271 Cheonbo-ro, Uijeongbu 11765 , Korea

TEL: +82-31-820-3574 FAX: +82-31-847-2894

E-mail: cmss21@catholic.ac.kr

ORCID: https://orcid.org/0000-0002-6383-8754

(c) This is an open-access article distributed under the terms of the Creative Commons Attribution Non-Commercial License (http://creativecommons.org/ licenses/by-nc/4.0/), which permits unrestricted non-commercial use, distribution, and reproduction in any medium, provided the original work is properly cited. Copyright (C) 2019 The Korean Association of Oral and Maxillofacial Surgeons. All rights reserved.
}

Congress was held in Hawaii. The ACOMS will be held again on Jeju Island in 2022.

This 60th congress discussed various contents from many fields of oral and maxillofacial surgery as well as research on medication-related osteonecrosis of the jaw (MRONJ), guidelines on anticoagulants and antithrombotic drugs, and ethics related to research.

The congress contained many joint symposiums with other societies, associations, and academies that have formed sisterhoods or MOUs with KAOMS such as KAOMS-JSOMS (Japanese Society of Oral and Maxillofacial Surgeons), KAOMS-TAOMS (Taiwanese Association of Oral and Maxillofacial Surgeons), KAOMS-PCOMS (Philippine College of Oral and Maxillofacial Surgeons), KAOMS-KAOPOM (Korean Academy of Orofacial Pain and Oral Medicine), KAOMS-KDSA (Korean Dental Society of Anesthesiology), and KAOMS-KAO (Korean Association of Orthodontists).

In addition, a commemoration ceremony for the 60th anniversary was performed at this congress and included videos introducing the oral and maxillofacial surgeons and their practices.

The Journal of the Korean Association of Oral and Maxillofacial Surgeons (JKAOMS) is the official journal of KAOMS and has published many papers on oral and maxillofacial surgery since 1975, introducing many advances and clinical developments in the field of oral and maxillofacial surgery. In 2012, the JKAOMS started publishing in English, increasing its potential for globalization. To achieve status as an academic journal influencing oral and maxillofacial surgeons around the world, JKAOMS has made the effort to expand its readership worldwide and to create indexes in the world's leading knowledge databases. JKAOMS has been indexed to PubMed Central, Google Scholar, ESCI, and SCOPUS. Due to this, JKAOMS is becoming a global academic journal with increasing citation. 
To improve the quality of academic journals, the editorial committee has invited review articles and special articles on various topics. To hinder plagiarism in submitted papers, it has used cross checking and basic database tools such as cross-ref and cross-mark since 2013. The JKAOMS is published in full open access and maintains international publication ethics.

Congratulations again on the 60th anniversary of KAOMS, providing an opportunity to look back on the past 60 years and forward to the 100th anniversary. I hope KAOMS continues to grow as an academic association contributing to development of oral and maxillofacial surgery not only in Korea, but also in Asia and the world.

\section{Conflict of Interest}

No potential conflict of interest relevant to this article was reported. 